\title{
Desalination Projects in Algeria: What Are the Environmental and Economic Issues of Seawater Desalination?
}

\author{
Abderrahmane Djoher \\ Faculty of Economic, Management and Commercial Sciences, University of Mohamed Ben Ahmed, Algeria
}

Received December 8, 2018; Revised April 15, 2020; Accepted May 13, 2020

Copyright $\subseteq 2020$ by authors, all rights reserved. Authors agree that this article remains permanently open access under the terms of the Creative Commons Attribution License 4.0 International License

\begin{abstract}
Nowadays, water resources fluctuate between the extremes. In one hand cyclones, floods and other climatic events provide water in overabundance, and on the other hand drought and desertification cause paralyzing scarcity and wretched living circumstances for the populations. This contrast between scarcity and abundance covers the whole planet, whether within the developed countries or within the developing countries. Algeria experienced more than a decade of drought, during which the conventional water resources were unable to satisfy the needs of the population, and this situation incited the Algerian authorities to look for other resources in order to ensure the provision of drinkable water to the population. The most adapted solution, which does not depend on the climatic riskiness, consists in seawater desalination. The objective of our paper is to show why Algeria opted for the desalination as a miracle solution for the problem of water scarcity and drought in the country. In one hand, Algeria is affected by the impacts of the global climate changes: abnormal temperature rise, drought, severe storms, a very low rainfall in the western regions and very high rainfall in the eastern regions of the country; and on the other hand, the desalination process has somehow solved the problem of drinkable water. Seawater desalination is sometimes presented as a miracle solution for the problems of scarcity in drinkable water. Besides being financially inaccessible to the poor countries (in terms of revenues or oil), these technologies are large consumers of energy, moreover their environmental impact issue is by far not yet resolved. Usually, the execution of desalination plants is a means to workaround problems of wastage or bad governance of water and to escape from the necessary reforms.
\end{abstract}

Keywords Water, Environment, Desalination, Crisis, Scarcity, Drought, Brine

\section{Introduction}

Nowadays, drinkable water resources are scarce. In one hand cyclones, floods and other climatic events provide water in overabundance, and on the other hand drought and desertification cause paralyzing scarcity and wretched living circumstances for the populations. This contrast between scarcity and abundance covers the whole planet, whether within the developed countries or within the developing countries ${ }^{1}$. Water is very essential for life. It is one of the most abundant resources of the earth, covering about 3/4th of earth's surface. Though it covers earth's major portion yet there is severe shortage of potable water in many countries around the world mainly developing countries and Middle East region countries. The reason for this situation is that nearly $97.5 \%$ of earth's water is salt water present in oceans and remaining $2.5 \%$ is fresh water which is in the form of ground water, ice-mountains, lakes and rivers, which serves most human and animal needs. ${ }^{2}$ Water, a common good for the humanity, is in danger. Scarcity, depletion of groundwater, drought, pollution and drying, the global crisis of water becomes intensified day after day. Each eight seconds, a child dies after drinking contaminated water. Nonetheless, water became a highly remunerative good which was shamelessly appropriated by the large industries.

Currently, the world faces a major water crisis, which is attributed by the experts to the global warming, and giving

\footnotetext{
1https://www.partagedeseaux.info/Enjeux-environnementaux-et-econom iques-du-dessalement-de-l-eau

$2 \mathrm{https}: / /$ www.intechopen.com/books/desalination-and-water-treatment/d esalination-of-water
} 
rise to an increase of extreme climatic phenomena: drought or floods, and an increase of water consumption as a consequence of the population growth and expansion of its uses. The paradox is that some populations suffer from water scarcity, whereas $71 \%$ from the surface of earth is covered by water. This state incited many specialists, researchers, and operators in water sector to develop different techniques of seawater desalination for the purpose of satisfying the exponential demand of this precious liquid. It is true that about $39 \%$ from the global population are living at less than $100 \mathrm{~km}$ from the coast, whereas 42 towns populated by more than one million of inhabitants lack sufficient resources of fresh water in spite of the fact they are seaside towns. Within a context of climate change, drought and water scarcity, which tend to worsen due to a non-improvement of water use, desalination appears to be a very promising sector for multinational companies in water and environment, and many countries have significantly invested in this domain.

\section{Saving Water: One of the Major Challenges in the Coming Years}

- Like any resource, water is unevenly distributed and it is an exhaustible resource. In our continent, the quality of surface water and water tables are more and more degraded and we have to dig deeper to get less-polluted water. With increasing consumption, and knowing that all distributed water is of drinkable quality, it costs more and more for the local authorities to pick up, treat, convey and distribute water and also to retreat waste water, let alone the fact that new more protecting standards and aggravated pollution will increase these costs.

- Ecologic issue: Water resource is not inexhaustible in terms of quantity. After depleting the surface water tables we are now drawing from deeper water tables which were constituted after millions of years. Water resource is degraded also in terms of quality and hence requiring more and more treatment of a water resource which is more and more polluted by agriculture, animal rearing and industry, and our own treated waste water are going to feed the future water resource.

- Economic issue: Saving water will allow reducing the budget of the state and local authorities (your taxes), by blocking the investments allocated to reinforce the water and waste water networks, and the nuclear status quo and its partial and progressive abandoning upon the expiry of the life term of the nuclear plants which will be replaced by new ecological energies (solar, wind..). Saving water will reduce the local taxes, burdened by constantly increasing outstanding payments of charges. Saving water will allow each household possessing an additional purchase power.

- Social issue: The increase of rental charges leads to a real social fracture. With additional rental charges, thousands of households are no more able to pay water and energy consumption charges. The overall debt of outstanding payments is transferred by the social managers to the general councils and is cleared through your local taxes.

The world reserves of fresh water (see Table 1) are given in the following table, not considering ices, which are difficult to count and which are in fact partly consumed nowadays in the zones where they melt as a result of the global warming. Groundwater constitute the main reserves of fresh water of earth, the remaining resources are insignificant. Some countries have already started to draw from this groundwater reserve.

Table 1. World reserves of fresh water

\begin{tabular}{|c|c|}
\hline Mediums & Volume, $\mathrm{km}^{3}$ \\
\hline Snow and ice on the poles and mountains & 30 millions \\
\hline Groundwater at less than 500 meters of depth & 4 millions \\
\hline Groundwater at more than 500 meters of depth & 4 millions \\
\hline Water of all fresh water lakes & 100000 \\
\hline Water existing in the ground & 70000 \\
\hline Water present at any moment in the atmosphere & 13000 \\
\hline Water present at any moment in all rivers & 1000 \\
\hline
\end{tabular}

This is the case for example in India, which is drawing from its surface water tables, and it is about to deplete, in ten or twenty years, all its groundwater regulating stocks. Later, this country will be able only to use the annual flows of rainfalls reloading the surface water, and these flows of rainfalls vary from a year to another, and which would have infiltrated during the previous wet season. The Sahara countries (Algeria, Tunisia and Libya) exploit very large aquifers which have tremendous resources and can last for centuries on the basis of the current rate of exploitation. However, this water is expensive (pumping charges, costs of transfer to north in Libya, etc.), and this type of large fossil aquifers is relatively rare in earth. The reserves in salty water are obviously huge. They are estimated to 1,32 billion $\mathrm{km}^{3}$ in the oceans and $1000 \mathrm{~km}^{3}$ in salty lakes. The climate changes will modify the availability of water, since it is expected by the climate models that generally, rainfalls will increase, however the current climatic zones will shift towards the poles. In our longitude, for example, it will rain 
little bit more in Northern Europe, and little bit less in Southern Europe and in North Africa, and more to the south of Sahara and tropical regions. See the map 1 of the world climate change and the map 2 of Global physical and economic water scarcity:

Map 1. Water stress $2019 \mathrm{WRI}^{3}$

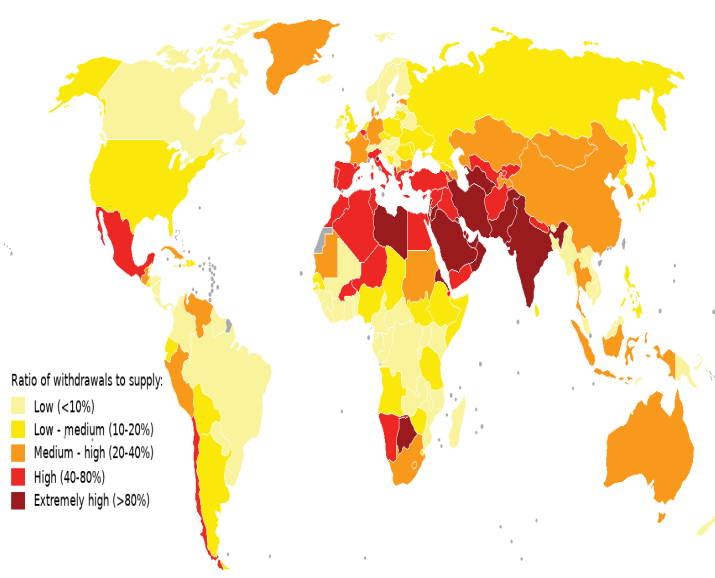

Map 2. Global physical and economic water scarcity Global physical and economic water scarcity

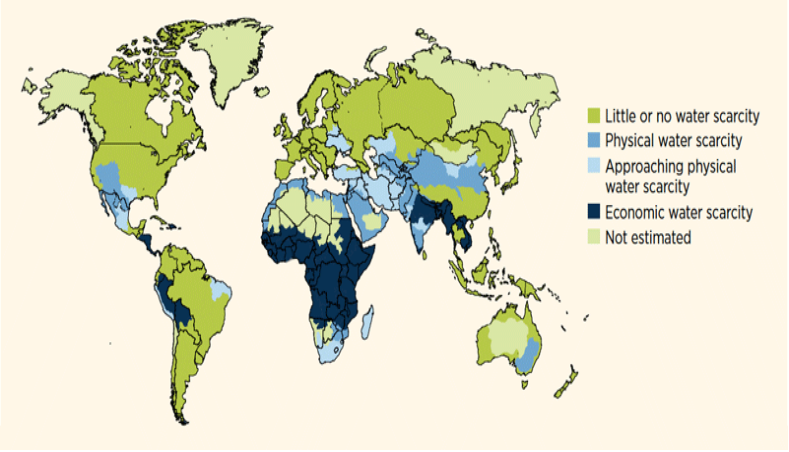

\section{Desalination: A Solution of Water Scarcity Problem}

Water desalination is the process by which we obtain fresh water (drinkable, or rarely due to cost, water usable for irrigation), from a salty or brackish water (seawater in particular). Despite its name, it consists rarely in removing salt from water, but rather the inverse, removing fresh water ${ }^{4}$. Seawater is salty, generally at about $35 \mathrm{gr} / 1$. In regions like the Persian Gulf, salinity reaches 42 gr/l. In

\footnotetext{
${ }^{3}$ https://en.wikipedia.org/wiki/Water_scarcity

${ }^{4} \mathrm{An}$ article from Wikipedia, the free Encyclopedia
}

order to separate salt, from a purely theoretical point of view and without losing energy (isentropic desalination), we need 563 watt-hour per $\mathrm{m}^{3}$. Seawater desalination is sometimes presented as a miracle solution to the problems of scarcity in drinkable water. Besides being financially inaccessible to the poor countries (in terms of revenues or oil), these technologies are large consumers of energy, moreover their environmental impact issue is by far not yet resolved. Usually, the execution of desalination plants is a means to workaround problems of wastage or bad governance of water and to escape from the necessary reforms.

Water desalination is usually conceived as a magic solution of these problems, save of course for the countries without access to sea (Mali, Niger). Since 97\% from the earth water is salty water, desalination may be regarded as a reasonable solution to the thirst of man, particularly in a time of emerging challenges related with the quality of water, its rareness and the quality of infrastructures are becoming more and more pressing around the world. The rate of construction of desalination plants increases in oil countries (Gulf, Algeria) and in the regions of rich countries suffering from drought (Israel, Spain, Australia, California, Florida or Texas in the United States of America). Their capacity continues also to increase, and each newly constructed or projected plant is characterized by a new record in terms of performances or production. We estimate that currently 50 millions of cubic meter of water are produced each year by desalination, and this figure will at least double for the coming years.

New countries are now involved in desalination, like England. China has announced large investments in this domain, and set the objective to cover $37 \%$ of its needs in drinkable water in the seaside regions by 2020. Algeria announced at the beginning of 2008 the construction of one of the largest desalination plants in the world, for a cost of 250 million Dollar. Israel, which already has in Ashkelon the most important desalination plant in the world, announced three projects of similar size. A non-governmental organization reminds in particular that 1200 desalination plants around the world consume large amount of energy, and hence emit greenhouse gases. It is alarming from an anarchic development of this technology. According to this NGO, for each liter of desalinated water, there corresponds a liter of brine thrown in sea. Even though, it's difficult to know the real impact of such wastes, the first studies conducted in this subject seem to show that it is weak (rivers throw also many minerals in sea).

\section{Desalination and Its Techniques}

In fact, removing fresh water from brackish water or from seawater is a technique used since a long time, in particular in the countries and princedoms poor of water 
but rich in oil, and where the cost of energy required for desalination is not a problem. Historically, desalination appeared in this region in 1869 , when a plant of water distillation was constructed in Aden to provide the British Marines. This plant used the same technique, which is now considerably developed, but always consuming energy, and this technique provides nowadays half of the desalinated water produced in the world. The two main types of processes of seawater desalination do not have the same energy cost:

- The first technique, the thermal one, is based on distillation. It consists in heating seawater to produce a pure water vapor, which we then condense on beams of cooled tubes in order to obtain fresh water. It is implemented via two techniques, the MSF (Multi-Stage Flash distillation), which dates from the 1960's, and the MED (Multi-Effect Distillation), which is more recent. This type of process is not less consumer of energy: to produce 1 cubic meter of water, an MSF plant consumes 15.5 kilowatt-hours and an MED plant consumes 7.5 kilowatt-hours. More than three quarters of this energy is used to heat the seawater. The distillation plants are constructed near the power plants in order to recover the heat. The modern installations recover hydraulic energy produced by the spill of concentrated water at high pressure through turbines or heat exchangers, and this reduces nowadays the total consumption of a plant to 4 to 5.5 kilowatt-hours per cubic meter of produced water. The thermal distillation allows transforming salted water into vapor which is then condensed to obtain desalinated water. Multi-Effect Distillation (or evaporation) has been the dominant technology in seawater desalination since 1880 and until 1960. With the advent of Multi-Flash distillation in 1960, the Multi-Effect Distillation seemed to disappear, and the neglecting of this technique was more aggravated with the advent of the reverse osmosis technique. With the reverse electrodialysis process, salts are separated from water under the action of an electric charge.
- The second process, reverse osmosis, uses semi-permeable synthetic membranes, which let water passing, and hold salt. In order to filter seawater through the membrane, we apply an external pressure higher than the osmotic pressure of the system ${ }^{5}$. The reverse osmosis requires the application of a pressure on the water introduced in the system, which is then, forced to flow through a semi-permeable membrane and holding most of the salts. Reverse osmosis appeared in the 70's following the design of semi-permeable membranes which are efficiently able to separate salts from water under pressure. Sometimes called hyperfiltration, reverse osmosis is considered as the most complex of membrane separations processes.

The core of desalination process is based on the reverse osmosis technology (see Diagram 1), however being isolated, it does not produce sound drinkable water and does not ensure an efficient system ${ }^{6}$. In reality, the energy recovery system is the key factor determining the electric costs of the installation. This latter has to be thoroughly chosen in terms of local energy costs and environmental policies. Furthermore, the disposal of brine may represent an environmental and economic problem in some regions where the fauna and flora are sensitive to the localized rise of salinity. The disposal of brine must be studied on a case by case basis. The desalination art consists in determining and combining the current technologies in order to optimize the quality of water and costs of production. And in order to customize our desalination units to your needs, we offer containerized mobile units starting from the intake of water until its distribution and for a production capacity up to $200 \mathrm{~m}^{3} / \mathrm{h}$ of desalinated water ${ }^{7}$.

- Different quality of water may be obtained from a desalination unit: Drinking water WHO, Irrigation water, Process water: water feeding boilers, and cooling water, Demineralized or ultrapure water.

- All types of natural sources of seawater may be treated: Surface seawater, Deep seawater, Brackish water from rivers, Coastal wells.

\footnotetext{
${ }^{5}$ The osmotic pressure is the pressure of equilibrium between a solution (here salted) and its pure solvent, separated by a permeable membrane of unique solvent. 


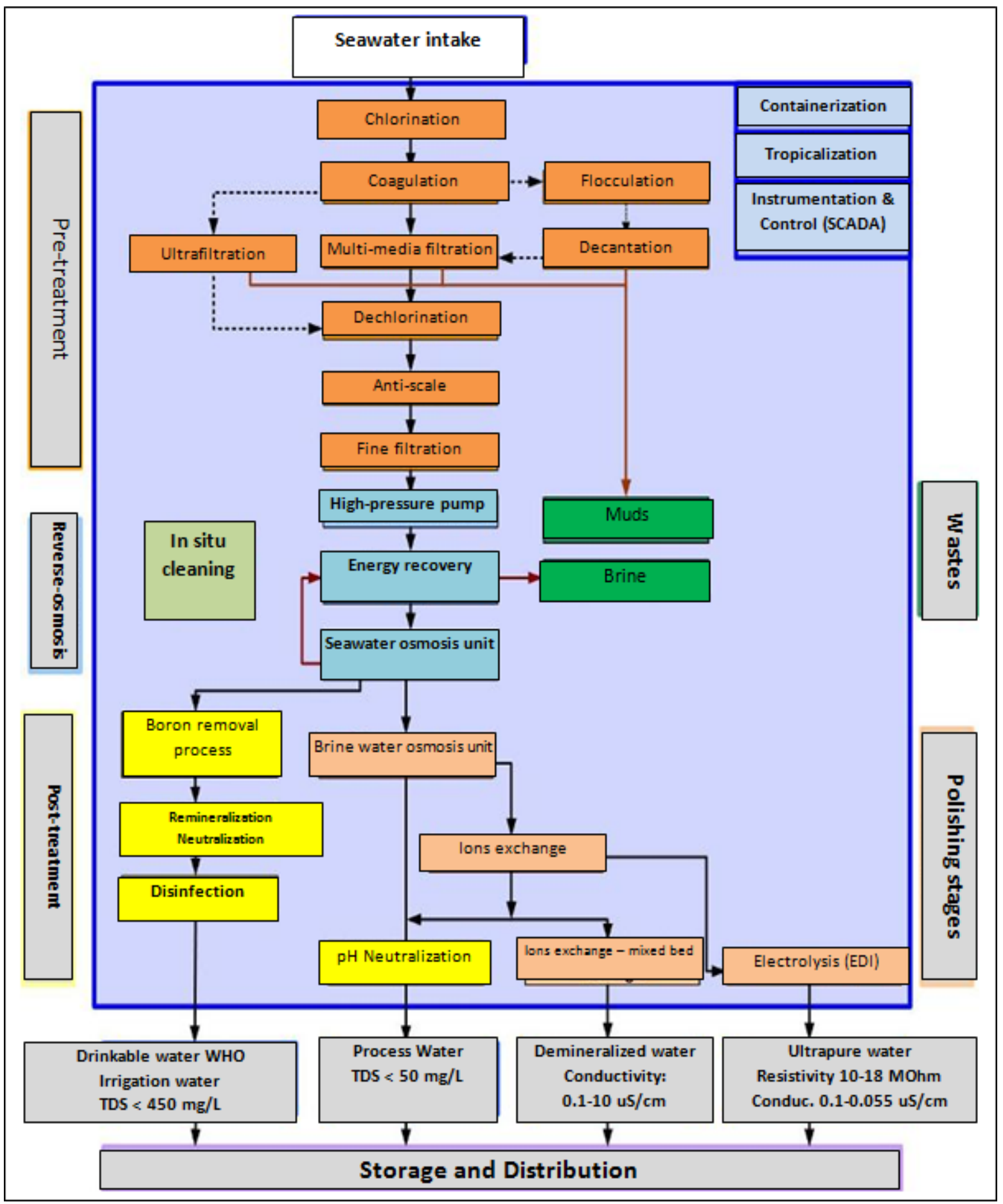

Diagram 1. Main stages in the desalination process ${ }^{8}$

This technology is very popular in many regions in Middle-East, Caribbean, and everywhere where desalinated water is the main source to feed cities and municipalities. However, it is also used in United States of America, Japan and in Europe to produce ultrapure water for many industries, in particular for the agribusiness and electronics. 


\section{The Challenges of Seawater Desalination: Economic Problems}

One of the main drawbacks in the membrane technology is its cost. Two factors contribute in making this technology expensive ${ }^{9}$ :

- The first factor is the quantity of energy consumed by the pumping systems (see Graph 1), in particular for the high pressure reverse osmosis: (high energy cost)

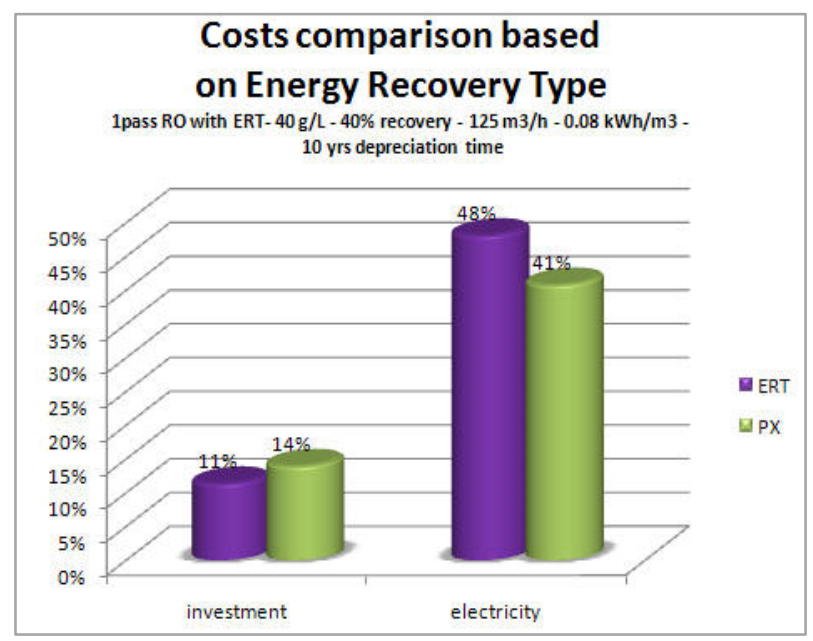

Graph 1. Cost of electricity and investment of the reverse osmosis ${ }^{10}$

- The second factor is the deterioration of membranes, a phenomenon which was subject to many researches. The membranes used for the reverse osmosis are chemically cleaned after many months of service. At the long term, the membranes are replaced when they become too stained and their performance drops significantly. Generally, this occurs each 3 to 5 years.

Other processes exist, and they rely on the exchange of ions (by electrolysis), and even on another membrane technology by microfiltration (or even nanofiltration, or ultrafiltration). Today, desalination costs in average 0.5 USD per cubic meter, the price varies according to the scale, the electric needs (or from other energy source) and the distribution. It is evident that this does not satisfy the needs of poor peasants of our planet, who are in fact the main victims of the water crisis. Furthermore, it appears clearly that desalination is not suitable to ensure the feeding of irrigation water. According to Texas Water Development Board, the cost of one cubic meter treated by distillation lies between 0.95 and $1.04 \mathrm{USD}$, whereas it is 0.84 USD for water treated by reverse osmosis. ${ }^{11}$

The reverse osmosis technology, since it exists two families of desalination technology: distillation and

9 https://www.partagedeseaux.info/Enjeux-environnementaux-et-econom iques-du-dessalement-de-1-eau

$10 \mathrm{http}: / /$ www.lenntech.fr.

11 https://www.partagedeseaux.info/Enjeux-environnementaux-et-econo miques-du-dessalement-de-1-eau membrane filtration. Distillation uses evaporation, through thermal heating, in order to separate water from salt impurities. Its main drawback consists in the energy consumed by this process. Membrane filtration uses the reverse osmosis process in order to hold salts contained in water (see Graph 2).

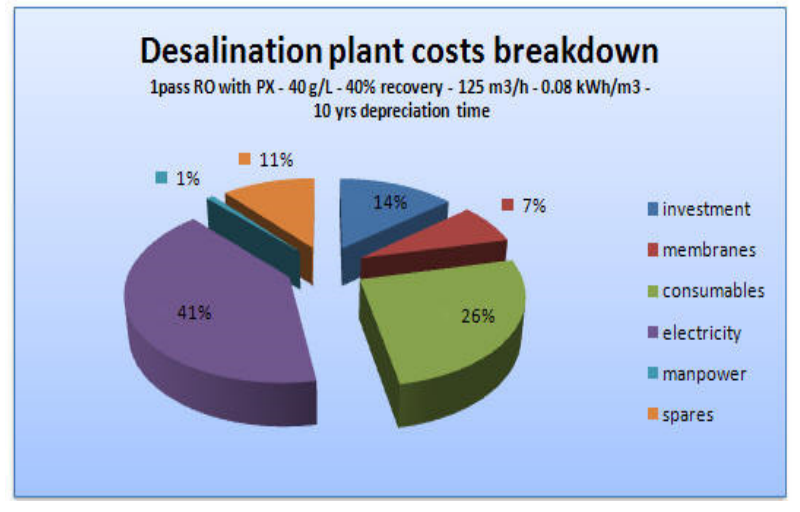

Graph 2. The financial analysis of desalination process by reverse osmosis

Salt water penetrates thus in an extremity from the membrane under a pressure of 80 bar, and after passing through the membrane, water leaves cleared of $99 \%$ from its salt. Today, the costs of reverse osmosis become lower than the cost of distillation in 1995, thanks to the advent of the new generation of membranes. Since 10 years, the costs of production of desalination were divided into two. According to their area of installation, nature of raw water and cost of energy, the produced cubic meter costs from 0.30 to 0.91 Euro for the reverse osmosis at its exit from the plant $^{12}$. The production of drinkable water from seawater is now an affordable solution when no other source of fresh water is available. The cost of investment is not the most important considered aspect. In fact, the consumption of chemicals and electric products are the driving operational costs.

As per the local energy costs, the choice of energy recovery system may be critical. The investment cost is higher with a pressure exchanger (PX) however the electric costs are lower. In countries with high electric costs, typically islands without any energy resource, financial economies with PX are more significant.

In Saudi Arabia, the real cost of desalination and water transport, no doubt huge, is a state secret. Nonetheless, $70 \%$ from the drinkable water in this country comes from desalination, a high figure which we also find in other Gulf countries, like Bahrain, Kuwait and United Arab Emirates. In these oil-producer countries, the low cost of energy allows adopting desalination at a large scale, which cannot be sustained by most of countries suffering from water stress, let alone the countries with no access to sea. Consequently, desalination seems to impose itself as an

12 Water to drink, the matic files. Technopole of Cherbourg, March 2005, p. 11 . 
immediate and strategic solution for the countries suffering from scarcity in water resources or water stress ${ }^{13}$. Water resources in Algeria will reach their limits by $2020-2025^{14}$. The climate crisis will aggravate the degradation of natural resources in the high plains and all steppic regions which represent real agricultural potentials. And "which are to ensure the food security" of Algeria, according to the director of the Algerian national agency for climate changes. According to the prospects of the desalination research center in middle-east, Algeria will be ranked after Saudi Arabia, United Arab Emirates and USA in terms of capacity of drinkable water production from seawater ${ }^{15}$.

Desalination in Algeria is regarded as a strategic solution as it will surely replace natural water resources in the great majority of coastal cities in the northern part of the country. Whatever the processes in use, desalination plants produce large amounts of wastes essentially in the form of very salty mixtures (brines). In addition, hot water and chemicals can also be rejected. Those effluents could be considered as an environmental contamination risk to the immediate and the close ecosystem. It is therefore of utmost importance to deal with the downstream impact of such rejects. Considering the huge amounts of money invested in this field, the priority should also be put on prevention and remediation measures whose cost should be imperatively included in the global cost of such projects. ${ }^{16}$

In the context of the economic stimulus plan started in April 2001 by the government, water sector represents a main part from the expenses ${ }^{17}$. The objective is to improve the service of water distribution by starting a pricing reform, reducing the wastage in the networks, estimated to $40 \%$, an increased mobilization of resources, and finally the involvement of the private operators in the management of drinkable water feeding networks. Consequently, the recourse to seawater became an advantageous solution in a country where dams are no more able to cover all the needs. Water resources in northern Algeria, where live most of the population, are limited. The situation was aggravated by a drought which persists for two decades. The production of drinkable water allocated for the consumption of the urban population is estimated today to 1.2 Billion of $\mathrm{m}^{3}$, which means an average provision of 100 liter/day per habitant. By 2020 , the population will practically double. The current demand of irrigated agriculture is huge, yet partly non-satisfied, of about 600 million $\mathrm{m}^{3}$. By 2020, and if the development plans are implemented, the demand of irrigation water will be threefold ${ }^{18}$.

In Algeria, investment in seawater desalination

13 F Galland, Desalination geopolitics, note of FRS No. 18/2008, September 2008, p.7.

14 http://eau.apinc.org/spip.php?article543.

15 Out of the 35 millions of inhabitants, more than 9 millions live in the 5 main cities of the countries, all located near the sea.

$16 \mathrm{http} / / /$ agrobiologia.net/online/wp-content/uploads/2014/03/75-81-BES SENASSE-7p-ok.pdf

17 Water sector in Algeria, economic mission, MINEFI, 2005.

18 National plan of water: a master plan for the management of hydraulic resources in northern Algeria; http://www.oieau.fr represents an important proportion from the direct foreign investment in energy sector, in which hydrocarbons hold the lead. The program initiated in 2001 projects the construction of 43 desalination plants from now to 2019 , for a total investment of about 14 Billion USD. The desalination technique is more expensive than the reverse osmosis. This technique is appropriate only if we construct a power plant simultaneously, since the thermal plants consume huge energy. Without this, the cost of cubic meter of water may reach up to 4 Euro, which is completely unaffordable for most of the countries. Nevertheless, the process which allows transforming seawater to fresh water consumes lot of energy, and hence expensive, and even the future plant of Makta, presented as particularly profitable, will invoice the cubic meter of water at 34 Dinar, about half dollar, and this remains too expensive as compared with fresh water generated by dams ${ }^{19}$.

According to the forecasts of Media Analytics Limited (Global Water Intelligence), "desalination industry will reach 64.3 millions of liters per day in 2010, and 97.5 millions in 2015. This represents an increase in capacities of $140 \%$ since 2005 . This growth requires an investment of 25 Billion USD from now till 2010 and 56.4 Billion USD before the end of 2015. In accordance with the current trend, more than half of these investments will be provided by the private sector, which makes desalination sector the most international part of water industry, in addition to being the most one relying on high technology" 20 . WWF reminds in particular that desalination plants consume so much of energy and consequently emit greenhouse gases. There is a fear that the new plants of seawater desalination will require the deployment of installations for the production of nuclear energy; such as Qatar and Ras Laffan project, which will be the largest power plant and seawater desalination of the country, with a daily production of $2.730 \mathrm{MW}$ of electricity and $286.000 \mathrm{~m}^{3}$ of desalinated water.

Jordan and China went well far, by signing a nuclear cooperation convention, opening the way for an upcoming cooperation in the peaceful use of nuclear energy, especially in the fields of electricity production and water desalination. A convention of cooperation between Algeria and France for nuclear desalination was signed in December 2007. However, the public authorities of water and desalination industry seem to be turned towards the establishment of still larger plants related to each other. In this context, Western Australia State, by constructing the plant in Perth, has issued a rule: the energy consumed by a desalination plant must be sourced from a renewable energy. This means that the states are bound to add to their electricity production network, a wind farm or a solar farm with a capacity equivalent to the consumption of their desalination plants ${ }^{21}$.

$19 \mathrm{http}: / /$ maghrebinfo.20minutes-blogs.fr;

$20 \mathrm{http}: / /$ infos-eau.blogspot.com/

21 The rush towards seawater desalination, Les Echos, December $15^{\text {th }}$ 2007. 
The Algerian economy is witnessing currently a significant growth, thanks mainly to the rise of oil and gas prices in the world markets during last years, and also to the strong demand in these sectors. Therefore, Algeria launched a process of development of its infrastructures, thanks to the financial means, and which would allow it setting the country into its way after more than a decade of serious turmoil: highways, dams, power plants and seawater desalination plants.

\section{Environmental Problems}

- Disposal of concentrated brine, which is double than the concentration of natural salinity, in sea or injected in soil;

- Disposal of hot water in sea, in the case of distillation;

- Use of chemicals for the cleaning of membranes (chlorine, etc.);

- Traces of copper, exhausted from the facilities;

- No special legislation related with the drinkability of water produced from such treatments;

- Use of lands for the construction of plants.

Generally, each desalination plant must be accompanied with an energy production unit. Obviously, this latter generates a large quantity of greenhouse gas, and such gases will have a negative impact on the climate and water cycle. However, in most of the cases, desalination became precisely necessary as a result of changes in the climate and water cycle. Some are afraid that the increase of numbers of desalination plants will require a boost of nuclear plants construction to a large scale: each desalination plant will therefore be accompanied by its own nuclear plant. There are desalination plants project coupled with renewable energy sources (wind and solar), such as in Perth (Australia).

There is also the problem of brine. A desalination plant generates a large quantity of brine, composed of various salts, heavy metals, organic compounds, etc. If such brine is thrown in sea, this will engender a large disequilibrium in the physical and chemical composition of seawater, with dramatic consequences on the biodiversity. Saudi Arabia simply disposes of its salts in a unique area in the Persian Gulf, a very rich ecosystem where fresh water of the continent is mixed with the salty water. There are only two similar mediums in our planet, called also an intermediary zone, in Arabia and in Vietnam. However, the rise of salinity has transformed the coast to lifeless desert, causing the disappearance of villages and local fishermen. In some places, brine is injected in the subsoil, yet this type of operations has given rise to concerns.

Desalination plants throw brine (concentrated salt) in sea, in addition to acidic solutions used in the pre-treatment to get rid of the bio-fouling and prevent the formation of scale. These solutions reduce slightly the $\mathrm{pH}$ of water, which drops from 8.3 (seawater is slightly alkaline) to about 7, i.e. the neutral PH. The residual acidity is rapidly removed by seawater. Even at some meters from the discharging place, the impact is negligible, as far as we can measure it.

Therefore, acidity does not cause a problem if the spilled solutions are rapidly diluted and scattered. However, this is not the case for brine, which increases the salinity rate in water. And this can prejudice the marine ecosystems. In Spain, studies conducted in laboratory and in field by the team of José Luis Sanchez-Lizaso, from Alicante University, showed that the aquatic flowering plant Posidonia oceanic ${ }^{22}$ (picture $N^{\circ} 1$ ) is too sensitive to the changes in salinity rate within its natural habitat. Important impacts on the structure of the plant were observed at salinity rate of only $39.1 \mathrm{gr} / 1$ and on its vitality starting from $38.4 \mathrm{gr} / \mathrm{I}^{23}$. This is because the main risk comes from salt. In occidental Mediterranean Sea for example, natural salinity of seawater ranges from 37 to 38 grams per liter, whereas the salinity of osmotic concentrate may reach 70 gr $/ 1^{24}$.

Desalination processes produce large quantities of brine, possibly at above ambient temperature, and contain residues of pretreatment and cleaning chemicals, their reaction byproducts and heavy metals due to corrosion ${ }^{25}$.

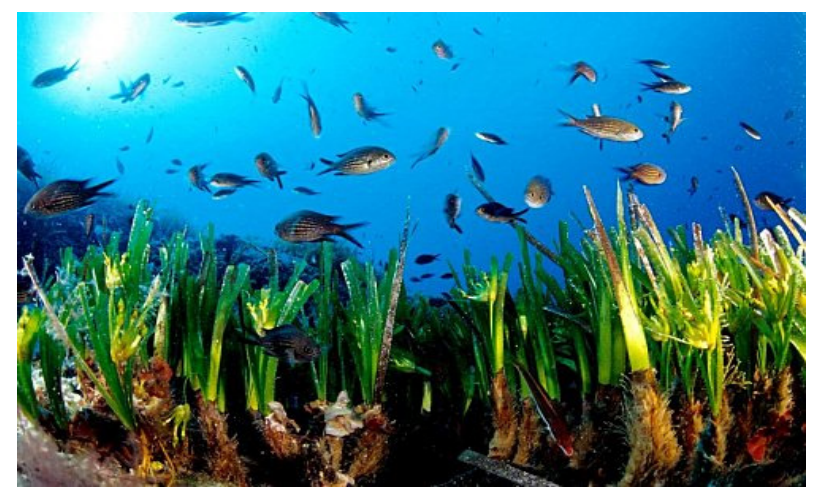

Picture 1. "Maritime photo of the aquatic flowering plant Posidonia oceanic"

Chemical pretreatment and cleaning are a necessity in most desalination plants, which typically includes prevention of biofouling, scaling, foaming and corrosion in thermal plants, and of biofouling, suspended solids and scale deposits in membrane plants. ${ }^{26}$ To limit the environmental impact of returning the brine to the ocean, it can be diluted with another stream of water entering the

22 Mediterranean tapeweed (Posidonia oceanica), an aquatic flowering plant, too sensitive to the changes of salinity rate. These herbariums constitute a very important ecosystem in Mediterranean sea, and they play a protective function of littorals against marine erosion. These herbariums are the refuge of a large number of animal species (mollusks, fish, shellfish, etc. )

23 J.L. Sanchez-Lizaso, et al, Desalination, 221, 602, 2008.

$24 \mathrm{http}: / /$ www.larecherche.fr;

25 Greenberg Joel, (March 20, 2014) "Israel no longer worried about its water supply, thanks to desalination plants" Archived March 24, 2014, at the Wayback Machine, McClatchy DC.

26 Lattemann, Sabine; Höpner, Thomas (2008). "Environmental impact and impact assessment of seawater desalination". Desalination. 220 (1-3): 1. doi:10.1016/j.desal.2007.03.009. 
ocean, such as the outfall of a wastewater treatment or power plant. With medium to large power plant and desalination plants, the power plant's cooling water flow is likely to be several times larger than that of the desalination plant, reducing the salinity of the combination (see figure 1). Another method to dilute the brine is to mix it via a diffuser in a mixing zone. For example, once a pipeline containing the brine reaches the sea floor, it can split into many branches, each releasing brine gradually through small holes along its length. Mixing can be combined with power plant or wastewater plant dilution. Brine is denser than seawater and therefore sinks to the ocean bottom and can damage the ecosystem. Careful reintroduction can minimize this problem.

\title{
Fig.1 Le dessalement en Méditerranée
}

\begin{abstract}
SUR IE POURTOUR DE LAMEDITERRANEE, $76 \%$ de la production d'eau douce est assurée par des installations d'osmose inverse. les plus grosses usines sont situées en Espagne, en Israēl et en Algérie, ainsi que dans certaines grandes îles, comme les Canaries. La carte indique toutes les installations produisant plus de 1000 mètres cubes par jour. la salinité moyenne de la mer Méditerranée est de 36 à 39 grammes par litre mais elle s'élève à 40 grammes par litre dans la mer Rouge et atteint 270 grammes par litre dans la mer Morte (en Israël).
\end{abstract}

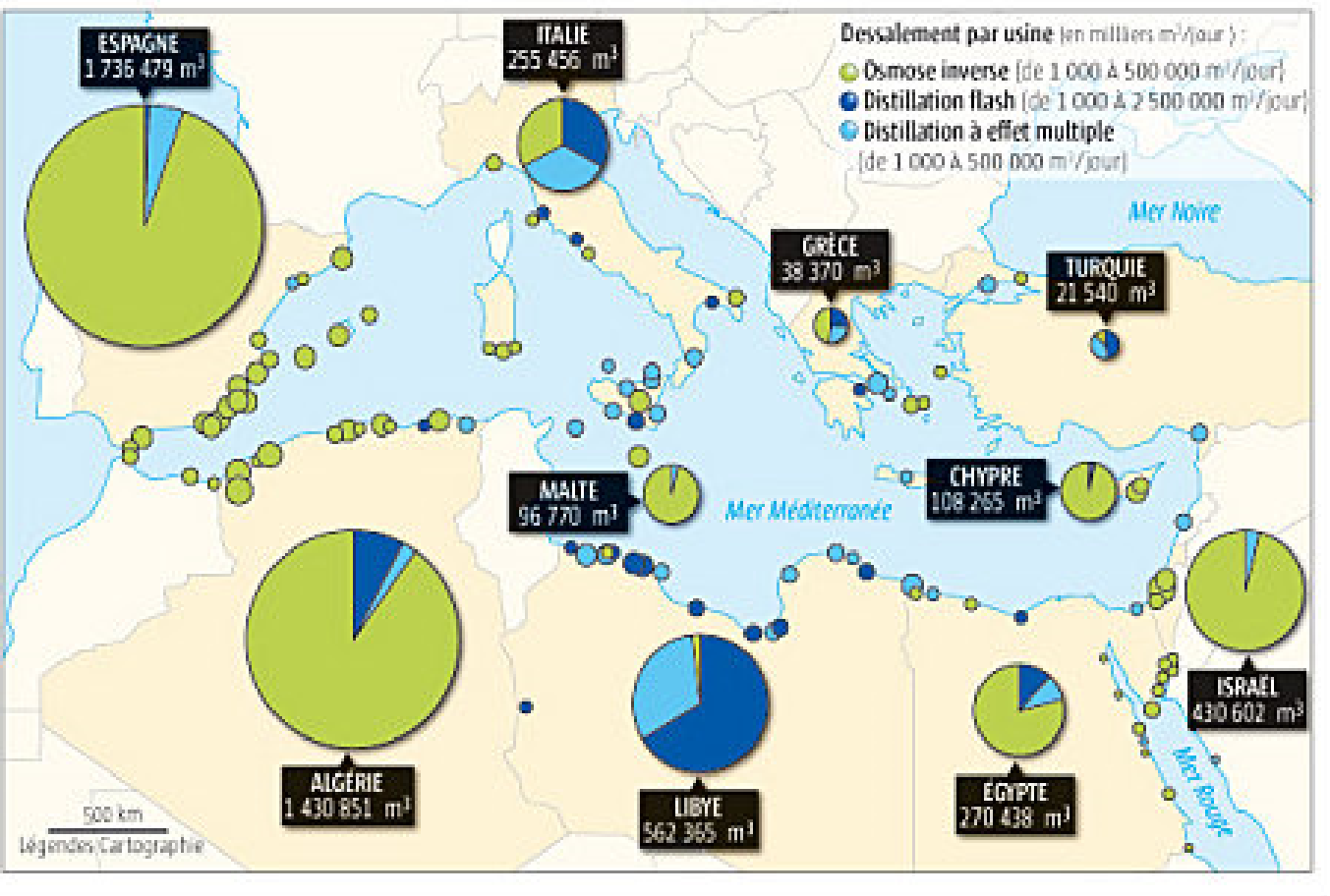

Figure 1. Countries using desalination in the Mediterranean region ${ }^{27}$. 
The strong tenor in concentrated salt thrown with the reverse osmosis may cause prejudice to the beds of Posidonia, classified as propriety habitat by the European directive for the conservation of fauna and flora habitats. A recommendation urges to avoid the disposal of wastes in this ecosystem and to rigorously observe the thresholds of salinity. In Australia, a large plant of reverse osmosis constructed in Perth, has been also warned by the local authorities to limit salinity of its wastes to $1.5 \mathrm{gr} / 1$ over the levels measured at 50 meters from the place of spills in order to abide by the applicable legislation in the country ${ }^{28}$. To fulfill this requirement, a diffuser system installed on the spillway doses with precision the mixture and the dilution of the concentrate at the place of spill.

Chemicals wastes raise other concerns, in particular for the plants with distillation. Chlorine is used to limit the biological contamination of the installation. It is a very efficient biocide, and when it is released in marine medium, it may affect non-targeted organisms. In light of the toxicological data related to a wide range of marine species, The United States Environmental Protection Agency (EPA) has thus issued a recommendation fixing the maximum limit of chlorine concentration in seawater to 7.5 micrograms per liter on long-term. The wear of equipment obliges the replacement of tubing during the life cycle of a facility. However prior to this replacement, copper may accumulate in the sediments and marine biotope ${ }^{29}$. There is an estimation of 300 kilograms per day, the total wastes of copper thrown from all distillation plants in the Gulf $\mathrm{f}^{30}$.

In Algeria, the seawater desalination program projects the construction of 21 plants from different capacities, producing in the long term 2.26 millions of cubic meter per day. Regarding the connecting of households to the drinkable water feeding network, the report states that it increases from $78 \%$ in 1999 to $92 \%$ in 2007 , whereas the daily provision increased from 123 to 165 liters per habitant. In addition to drinkable water feeding, the document highlights also the large developments realized in sanitary drainage, in particular the construction of 130 sewage treatment plants, and an increase of $80 \%$ of the length of the national sanitary drainage network, the figure increased from 21.000 to $38.000 \mathrm{~km}$. ${ }^{31}$

The entry into service of these infrastructures allowed making available an installed capacity of treated sewage of 270 million $\mathrm{m}^{3}$ /year, which will then pass in 2009 to 600 million $\mathrm{m}^{3} /$ year, which means a capacity of sewage treatment of $82 \%$. In the agricultural hydraulic domain, the irrigated area, which was 350.000 hectares in 1999 , increased to 860.000 hectares. The quantity of water stored

28 Welker Environmental Consultancy for Water Cooperation. Perth Metropolitan Desalination Proposal. Environmental Protection Statement, 2002.

29 S. Lattermann and T. Hopner, in protecting the Gulf's Marine ecosystems from Pollution, by A. Abuzinada et al. Birkhauser Verlag, Switzerland, 2008.

$30 \mathrm{http}: / /$ www.eco-life.fr.

31 Ministry of water resources. in Algerian dams reached a rate of filling of $52.63 \%$ in April $3^{\text {rd }}$ against $44.89 \%$ at the same period in year 2007 . The volume of water collected by 59 operating dams increased to 3.06 Billion $\mathrm{m}^{3}$ by the start of April against 2.6 Billion $\mathrm{m}^{3}$ at the same period of year 2007 , i.e. an increase of $7 \%$. The last rains have fed, during March of the current year, additional volumes of water estimated to 341.39 million $\mathrm{m}^{3}$.

\section{Conclusions}

Natural resources, such as water, are and remain limited and finite. The promises of desalination are misleading. The unlimited abundance, in any domain whatsoever, is no more than an illusion. Seawater desalination may seem as a miraculous technology allowing the satisfying of our modern communities' needs. For some, this miraculous capacity extends until the policy domain, since desalination will constitute the key of the current Israeli-Palestinian conflict. Desalination is also a manner to workaround potential political conflicts related with the sharing of water, such as in Spain, where this solution has been finally preferred from the projects of large transfer of water between the different regions of the country.

Seawater desalination utilizes permeable membranes, which are only tasked to remove dissolved solids while dividing the feed water into purified water and the rejected concentrated salts. The salts and other organics are thrown into the brine stream then flushed into a drain. At the end we have purified water that has $99 \%$ less dissolved salts. These sea water RO systems are immensely powerful, with the capacity of purifying significantly high TDS water. ${ }^{32}$ In some cases, the promotion of desalination at a large scale is a means for the authorities to avoid tackling and solving the water governance problems in a headlong rush: hence, in Algeria, where the authorities could not improve the network since the independence of the country in 1962, or even in Australia, Israel and California, they avoid, for ideological or economic reasons, to reconsider lifestyles and production manner, which are particularly wasteful of water. $^{33}$

For this reason, it is necessary to focus on techniques targeting a reasonable use of water, the conservation of this resource and saving water. We need in particular to manage water and avoiding leakages which represent in average 20 to $30 \%$ from water consumption in the world. According to recent studies, it seems that conservation measures of this kind would be able to satisfy the needs of water for a cost representing only 10 to $25 \%$ from desalination costs. The efficiency of water use must be improved in this regard,

32https://www.pureaqua.com/seawater-reverse-osmosis-systems-swro/?u tm_source $=$ google\&utm_medium $=$ cpc \& gclid=CjwKCAjwvtX0BRAFEi wAGWJyZBbiJ2SxAPB tpVT430gh9DHdUl 3yuKgfhZQYHZuwtr L o4yB2kDxoCvvwQAvD BwE

33 http://www.entp.edu. $\bar{d} z /$ revue/files/article/50/article\%208.pdf 
and we have to get rid of leakages and wastage of water. According to Worldwatch Institute based in Washington, this would allow avoiding the recourse to desalination, which has negative impacts on the environment and atmosphere. Furthermore, we have to spare no efforts in the field of research and development in order to reduce energy consumption and wastes which have harmful environmental consequences. However, this knowledge must be accessible to everybody. In fact, the issue of access to drinkable water must not be solved to the detriment of large pollutions, whether in marine or air mediums. Finally, desalination projects must, as far as possible, integrate the logics of employment, development of industrial branches and establishment of companies. Therefore, it is important to implement programs of training, transfer of skills and technology in order to train and develop qualified manpower, a source of integration and acceptation of projects, but also adopting a long-term good management ${ }^{34}$; such as:

- Having a shower rather than a bath, would divide the consumption of water by at least three. A shower of 4 to 5 minutes requires the consumption of 30 to 80 liters of water, whereas for a bath, 150 to 200 liters is consumed.

- Controlling water leakages would allow reducing the consumption by $20 \%$. A leaking tap losses up to 120 liters.

- Closing the tap when water flows with no reason must be a reflex. In particular, during teeth brushing or shaving, responsible for wastage of water of 12 to 18 liters per each minute. Idem for dishwashing, rinsing a kitchenware under flowing water would lose up to 200 liters.

- Installing a mixer faucet allows saving $10 \%$ of water as compared with a classical mixer tap.

\section{REFERENCES}

[1] Collection of Chemical \& Engineering News, American Chemical Society, Washington, D.C.
[2] Léopold Mayer, Worldwatch Institute annual report «State of the World 2004», Washington, D.C. (translated into French by M.L. Bouguerra: The consumption assassinates. How a lifestyle of some ruins the lifestyle of other? Paths for a responsible consumption, Editions Charles-, Paris, 2005).

[3] F Galland, Desalination Geopolitics, Note of FRS No.18/2008, September 2008, p:7.

[4] J.L. Sánchez-Lizaso, et al, Desalination, 221, 602, 2008.

[5] M. L. Bouguerra in «Way of seeing. The Diplomatic World» No. 81, June-July 2005, p.41-44.

[6] M.L. Bouguerra, Water under threat, Zed Books, London, 2006.

[7] «Water, be careful it is fragile», Report in Pour la Science (Scientific American), Paris, January-March, 2008.

[8] Christiane Galus, « Seawater desalination, a very promising market », Le Monde. 2008.

[9] Henri Boyé, energy, desalination and climate change in the Mediterranean region, Plan Bleu, August 2008, p37.

[10] Welker Environmental Consultancy for Water Cooperation, Perth Metropolitan Desalination Proposal. Environmental Protection Statement, 2002.

[11] The rush towards seawater desalination, Les Echos, December 15th 2007.

[12] S. Lattemann et T. Höpner, in Protecting the Gulf's Marine Ecosystems from Pollution by A. Abuzinada et al., Birkhäuser Verlag, Switzerland, 2008.

[13] http://eau.apinc.org/spip.php?article543

[14] Water sector in Algeria, Economic mission, MINEFI, 2005

[15] http ://www.oieau.fr;

[16] http://maghrebinfo.20minutes-blogs.fr;

[17] http://infos-eau.blogspot.com/

[18] http://www.larecherche.fr;

[19] http://www.actu-environnement.com

[20] http://www.eco-life.fr 